\title{
The Value of Adapting Counseling to Client's Spirituality and Religion: Evidence-Based Relationship Factors
}

\author{
Amelia L. Evans * and Jennifer Koenig Nelson *
}

check for updates

Citation: Evans, Amelia L., and Jennifer Koenig Nelson. 2021. The Value of Adapting Counseling to Client's Spirituality and Religion: Evidence-Based Relationship Factors. Religions 12: 951. https://doi.org/ $10.3390 /$ rel12110951

Academic Editor: Kelvin Mutter

Received: 14 July 2021

Accepted: 27 October 2021

Published: 1 November 2021

Publisher's Note: MDPI stays neutral with regard to jurisdictional claims in published maps and institutional affiliations.

Copyright: (c) 2021 by the authors. Licensee MDPI, Basel, Switzerland. This article is an open access article distributed under the terms and conditions of the Creative Commons Attribution (CC BY) license (https:// creativecommons.org/licenses/by/ $4.0 /)$.
MA in Counseling Program, Bethel University, St. Paul, MN 55112, USA

* Correspondence: ale42385@bethel.edu (A.L.E.); jen94387@bethel.edu (J.K.N.)

\begin{abstract}
There is a strong tradition of attention to relationship factors in the field of counseling. The research on the importance of the relationship and adapting to client factors continues to grow, supporting the importance of professional multicultural competence. The field of counseling, specifically within the United States context, has focused on Multicultural Counseling Competencies with more recent emphasis on social justice through the Multicultural and Social Justice Counseling Competencies. Within these competencies, spirituality and religion are mentioned as multicultural components to consider as potentially salient to clients. Yet, there has been less emphasis on ways to adapt counseling to a client's spirituality and religion compared to other multicultural components of one's identity, such as race, gender, and culture. Historically, a lack of training, fear of causing offense, or concerns about influencing clients, resulted in clients' spirituality and religion being overlooked far too often in counseling. Despite this tendency, recent clinical evidence on relational responsiveness identifies the adaptation of counseling to a client's spirituality and religion as highly effective. In this article, the authors discuss how adapting counseling to a client's spirituality and religion, in relation to all multicultural factors salient to the client, enhances relational responsiveness and treatment effectiveness. The authors also discuss the implications for training, supervision, and practice.
\end{abstract}

Keywords: spirituality; religion; counseling; therapeutic alliance; evidence-based practice; multicultural competencies; cultural humility; relationship factors

\section{Introduction}

The foundation of the counseling process is identified throughout the literature as the therapeutic relationship. Research on the counseling relationship recognizes the essential inclusion of client multicultural factors in the therapeutic process to create strong bonds. Yet, the multicultural factors of religion and spirituality are often overlooked or glossed over within the counseling context because of apprehension around counselor training, influence, and competence on the inclusion of religion and spirituality in the counseling process. Religion and spirituality are identified as protective factors for clients. Moreover, with the COVID-19 pandemic and global experiences of suffering and loss, it "may intensify the need for clinicians to address spiritual and existential dynamics in psychotherapy, as clients struggle with tragedy and uncertainty that can challenge prior belief systems or prompt stronger seeking within their meaning systems" (Bell et al. 2021, p. 3). Therefore, it is imperative that counselors are trained to competently include all client multicultural factors including religion and spirituality into the counseling process. Adapting counseling to all multicultural factors salient to a client, including spirituality and religion, enhances the counseling relationship and treatment outcomes.

\section{Importance of the Relationship}

Counseling effectiveness research recognizes the significance of counseling relationship factors on treatment outcomes. Historically, outcome research focused on different treatment approaches to compare and determine best practice for different populations. 
From these numerous studies, meta-analyses revealed that different treatment approaches identified no significant differences in treatment outcome (Benish et al. 2008; Imel et al. 2008; Leichsenring and Leibing 2003; Wampold and Imel 2015). Yet, further studies identified common factors across treatment approaches that contributed more to variance of client outcomes (Wampold and Imel 2015). Relationship factors, one of the common factors, received considerable research attention because of its proposed 30\% account of change in counseling (Hubble et al. 1999). Relationship factors include numerous variables. However, of all the relationship factors, the therapeutic alliance, which consists of counselor and client agreement of counseling goals and tasks and the quality of the counseling relationship bond (Bordin 1979), is a predictor of outcomes with different treatment approaches, counseling topics, and measures (Wampold 2001; Norcross 2002; Castonguay et al. 2006). A consistent and important finding across measures and treatment approaches is that clients and counselors have different perceptions of the therapeutic alliance (e.g., Bachelor and Horvath 1999; Tryon et al. 2007). Yet, client perception of the therapeutic bond and agreement on counseling goals and tasks by session three is predictive of treatment outcome (Miller et al. 2010; Wampold and Imel 2015). Therefore, as significant predictors of treatment outcomes, the therapeutic alliance and client perception of the alliance must be prioritized within the counseling process.

In addition to relationship factors, another common factor, client extratherapeutic factors, requires consideration because of related client outcome evidence and impact on the therapeutic alliance. Client extratherapeutic factors have been projected to account for 40\% of change in counseling (Asay and Lambert 1999). These extratherapeutic factors encompass the internal and external resources, life events, and variables in a client's life that contribute to and hinder client change (Leibert 2011). Since client factors are the context out of which the client lives and makes change, it is important that counselors are attuned to variables outside of treatment that directly impact each client. For example, for clients who have low levels of extratherapeutic social support, the relationship bond between client and counselor plays a stronger role in positive outcomes than for those clients who have high levels of extratherapeutic support (Zimmermann et al. 2020). Given the influence of culture and spirituality in clients' lives, it is important to explore them as extratherapeutic factors which may be utilized within counseling for greater client benefit (Leibert and Dunne-Bryant 2015). With evidence confirming that outcome and direction of counseling are impacted by client factors (Leibert and Dunne-Bryant 2015), it is through attention to these client extratherapeutic factors that counselors can demonstrate awareness and consideration of the client's unique context and worldview. Focusing on what is most salient to the client offers the foundation for building an effective therapeutic alliance from a client's perspective and increases client outcomes.

\section{Multicultural Counseling Competencies}

The field of counseling's roots are firmly grounded in the relationship and therapeutic alliance, with more recent yet resolutely grounded roots in multicultural counseling competence. All counseling can be seen as a multicultural endeavor (Sue et al. 1992; O'Hara et al. 2021), with therapeutic change the desired outcome (Ridley et al. 2021a). In the almost 30 years since the original Multicultural Counseling Competencies (MCC) were developed by Sue et al. (1992), counselor education has seen much progress as many counselors have been trained in the beliefs/attitudes, knowledge, and skills originally proposed through the MCC (Gonzalez-Voller et al. 2020). Training based on these MCC covered a variety of important identities of clients, with some identities receiving more attention than others. Originally, the focus on race and ethnicity was the priority of these multicultural counseling competencies (Vandiver et al. 2021).

The MCC are seen as the inspiration for a holistic view of clients and the more recent focus on intersectionality of identities (Ratts et al. 2016). Through increased knowledge and research, this progress resulted in a major revision of the MCC to the Multicultural and Social Justice Counseling Competencies (MSJCC) (Ratts et al. 2015). Ratts et al. (2016) 
identify the prior "single-lens" focus on race or ethnicity of the original MCC and push for the "wide-angle" lens consideration of the intersection of various identities salient to clients. This focus on the intersectionality of identities recognized by the client ultimately strengthens the therapeutic alliance and thus the relationship (Jain et al. 2017).

Multicultural counseling competence must continue to evolve as we gain new understanding through research and societal changes (Ratts et al. 2016; Ridley et al. 2021b). Ratts et al. (2016) push for the importance of disseminating the MSJCC with students. They indicated the training of students must occur amidst counselor-educators and supervisors also working on the competencies for themselves. One of the ways this can occur is through a deeper consideration of the counselor's worldview. There is intentional focus in the MSJCC on self-awareness of the counselors in relation to their own worldviews and an understanding of clients' worldviews. Counselors are tasked to understand themselves, including their beliefs, values, and also their biases. "This internal awareness then extends to counselors' understanding of clients' worldviews and, subsequently, the ways in which culture, power, privilege, and oppression influence the counseling relationship" (Ratts et al. 2016, p. 37). How counselors "manage culture in the relationships requires a focus on the clinicians themselves-their awareness about their attitudes and feelings about their culture and the cultures of others" (Vandiver et al. 2021, p. 595). To put the MSJCC into practice, counselors are tasked to implement culturally responsive evidence-based practices (Gonzalez-Voller et al. 2020) while continuing the consideration of how the counselors' worldviews impact the counseling process and relationship (Ridley et al. 2021a). Through this focus, collaboration with clients helps determine the focus of counseling in order to move towards positive outcomes through appropriate consideration of the client's identities. With the intersectionality view of identities in the MSJCC, spirituality and religion are part of the cultural picture counselors need to consider.

\section{Multicultural Counseling Competencies: Considering Spirituality and Religion}

Although there is a clear push in the counseling field for considering the individual holistically in relation to the intersectionality of identities, the fear and challenge of bringing in spirituality and religion looms over counselors-in-training and those training them. This struggle is not surprising, given spirituality and religion were traditionally considered "taboo" in counseling and other mental health fields (Bergin 1980) and the focus of the MCC was originally on ethnicity and race (Sue et al. 1982, 1992; Vandiver et al. 2021). Not all that long ago, almost $40 \%$ of surveyed counselors-in-training noted being taught directly or indirectly that they should not be addressing spirituality and religion in counseling (Adams 2012). Since then, numerous authors indicate spirituality and religion are at best covered only marginally by many counselor training programs, and at worst entirely ignored in training (Magaldi-Dopman 2014; Scott et al. 2016; Pearce et al. 2019; Mintert et al. 2020). Without the proper training to consider and incorporate spirituality/religion in appropriate ways, "counselors might have been so concerned with respecting diversity and avoiding the imposition of counselor values that they did not assess for the relevance of clients' spirituality/religiosity to presenting concerns, thus preventing them from intervening appropriately" (Cashwell et al. 2013, p. 53). This lack of focus translates into the difficulty of not knowing how to work with spirituality/religion in counseling (Scott et al. 2016) and confirms in student minds that this is a taboo topic. Without specific training in spirituality/religion, counselors lack not only competence but also the confidence to address spirituality/religion in effective ways when sent out into the field (Pearce et al. 2019). Without intentionally addressing religion and spirituality in counseling programs, counselors-in-training will not consider spirituality and religion as potentially salient factors for clients (Mintert et al. 2020), missing important opportunities to best develop the relationship.

Given the shift to the MSJCC in 2016, this new push for focus on spirituality coincides with the shifts programs are making in light of the new competencies. In the United States, the Council for Accreditation for Counseling and Related Educational Programs 
(CACREP) standards (Council for Accreditation of Counseling and Related Educational Programs 2016) only added spirituality as a standard in this most recent version of the standards. The current standard is now a foundational expectation for counseling programs to show evidence of covering "the impact of spiritual beliefs on client's and counselor's worldviews" (Counseling Curriculum, F.2.g.). Many counseling programs in the United States are balancing the shift to the broad lens focus including intersectionality, from the prior narrow lens of the MCC, amidst also attempting to find ways to directly address spirituality to meet the new CACREP standard. In addition, counseling educators may themselves be uncomfortable with spirituality and religion and possibly pass this discomfort to counselors-in-training (Giordano and Cashwell 2014). One concern may relate to pushing values onto clients, thus avoidance of spirituality/religion topics is the typical response (Hook et al. 2019). "If faculty and supervisors are uncomfortable or unable to address these issues in counselor education programs, how will counselors-in-training or counselors learn to be open and comfortable with these topics and issues?" (Henriksen et al. 2015, p. 67). Given the newness of this spirituality standard and the potential fear of making spirituality and religion more explicit in training and practice, many programs include spirituality and religion under the multicultural/diversity umbrella to fit it somewhere, which often results in only cursory coverage of spirituality and religion in a multicultural counseling course, especially if they do not intentionally include spirituality and religion in their training. (Magaldi-Dopman 2014; Scott et al. 2016; Pearce et al. 2019; Mintert et al. 2020). As spirituality and religion continue to be key identity factors for some clients, counseling programs must keep this in mind as they continue to determine how to include spirituality and religion into training and practice in their programs, to best equip students to build effective relationships that lead to positive outcomes.

In 2020, almost half of individuals polled indicated religion as very important in their lives, fifty-three percent of respondents indicated religion can answer all or most of today's problems, and 58 percent indicated praying often outside religious services (Gallup 2021). Recent meta-analytic data indicates participation in public religious activities is significantly related to positive mental health outcomes, most likely related to the greater social support and coping resources that results from engagement in such activities (Garssen et al. 2021). Additional research highlights that not only is spirituality and religion important to individuals, but that spirituality and religion are identified as relevant and worth discussing in counseling (Harris et al. 2016). Yet, clients might avoid bringing up spirituality/religion for fear a counselor will judge or minimize the impact of spirituality/religion in their lives or worse yet, consider it problematic (Hefti 2011). Still, the importance of considering the spiritual and religious identities of clients has been heightened amidst the COVID-19 pandemic (Bell et al. 2021), with one quarter of individuals indicating a stronger faith because of the COVID-19 pandemic (Newport 2020). The disconnection from houses of worship and other public religious activities resulting from the COVID-19 pandemic were additional struggles for many individuals who find religion and spiritual activities as important in their lives. Moreover, in the United States context, amidst the COVID-19 pandemic, political strife, and racial tensions, the struggle to share about spirituality and religion may be increasingly difficult for clients. Clients who might have a particular political perspective might be fearful to bring up such with a mental health provider for fear of being judged or may choose to avoid counseling altogether (Pearce et al. 2019). This may be especially concerning when such a perspective is based on the spiritual and religious beliefs of importance to the client. Without specific training focused on the inclusion of spirituality and religion as relevant factors in multicultural counseling, and thus the relationship, many counselors have been ill-equipped to properly broach these topics during counseling in a way that shows the clients they will not be judged and that spirituality and religion are appropriate topics to discuss in counseling. However, the clear purpose of multicultural counseling competence should be therapeutic change for the client (Ridley et al. 2021a). Thus, when spirituality/religion are salient for clients, it is through addressing such that therapeutic change will be enhanced. 


\section{Implications for Practice, Training and Supervision}

In the wide-angle lens of the MSJCC, counselor educators and professionals in the field must advocate for the importance of addressing all relevant multicultural components in effective ways during training, including spirituality and religion (Jain et al. 2017; Ratts et al. 2016; Mintert et al. 2020). "A significant piece of identity for one client may not be for another. Some clients may weigh their race more heavily, others their sexual orientation, others their religion, and still many others the intersection of identities. Therefore, clinicians cannot assume what will be salient for any client" (Ridley et al. 2021a, p. 549). Identity intersectionality commands the consideration of clients' spirituality and religion in conjunction with other cultural variables to have a clearer picture of the uniqueness of the individual (Scott et al. 2016; Ratts et al. 2016). As spirituality and religion are significant for many individuals, professional cultural competence must include religious and spiritual competence (Whitley 2012).

Through the MSJCC and the new CACREP standard, there is a clear call to include spirituality and religion intentionally in the training counselors receive (Crabtree et al. 2020; Magaldi-Dopman 2014; Miller 1999). To effectively develop in MSJCC, training in their own beliefs, values, and biases are essential for counselors to understand how their own worldview may prevent or influence them when considering spirituality and religion with their clients (Scott et al. 2016). Integrating spirituality, religion, and worldview into counselor training is an essential part of the preparation for multicultural counseling competence training. It is imperative for counselors to see its importance throughout their training, not just as an "afterthought" in their multicultural counseling course (MagaldiDopman 2014). As counselor educators focus on the integration of spirituality and religion in counselor training programs (Mintert et al. 2020), counselor education should focus on preparing counselors to work with clients who may have similar spirituality and religion as well as those who are different from themselves (Gordon 2018; Ridley et al. 2021a). Additionally, the counseling profession needs to assure the competence of those already in the field-such as advocating for additional training, including online trainings such as the Spiritual Competency Training in Mental Health (Pearce et al. 2019), for those who did not have the opportunity to be effectively trained in how to ethically bring spirituality and religion into counseling. It is essential for professional counselors to know the evidencebased interventions that are applicable to working with spirituality and religion (Mintert et al. 2020; Gonzalez-Voller et al. 2020). The inclusion of spirituality and religion in the MSJCC training demonstrates a focus on what is salient to a client to impact therapeutic change through the counseling relationship (Ridley et al. 2021a; Vandiver et al. 2021).

\subsection{MSJCC and the Counseling Relationship}

Given the counseling field is still working to integrate MSJCC into its training and practice, it is not surprising that there will need to be clear efforts to include spirituality and religion in new ways moving forward. With the historical context of exclusion and concerns about imposing values, it is important that the inclusion of spirituality and religion into training and practice is based on the importance of the Evidence-Based Relationship and related factors (Parrow et al. 2019). As research on the importance of the relationship and adapting to client factors continues to grow, the counseling relationship and responsiveness to the client is now considered evidence-based practice (Norcross and Wampold 2019). Norcross and Wampold (2018) indicate adapting to the client's personal and cultural characteristics further expands the possibility of positive outcomes. As we consider the client's characteristics, culture, and preferences, which are all part of providing evidence-based practice, we are being responsive to the client. Specifically, being "relationally responsive" and adapting treatment for clients are considered evidence-based practices themselves and may account for more of the positive outcome with clients than the treatment (Norcross and Wampold 2018). Further, Hook et al. (2019) found that adapting for spirituality and religion has a strong evidence-base. Research indicates that adapting to a client's spirituality and religion showed positive outcomes in both psychological and 
spiritual functioning above no-treatment and alternative treatments that did not include adaptations for spirituality and religion (Hook et al. 2019). Based on the results of this meta-analysis, Hook et al. (2019) suggest educators and supervisors explicitly include spirituality and religion within all aspects of training. When religion and spirituality are salient to a client and we adapt counseling to these factors, this will impact not only how the client is conceptualized, but also the goals, the actual interventions chosen, as well as the interactions between client and counselor (Hook et al. 2019). As the MSJCC continue to be implemented into training and practice, it will be important to gather client feedback to ensure that the application of MSJCC enhances the therapeutic alliance and positive client outcomes. Hence, the Evidence Based Relationship (EBR) and related factors are an integral part of furthering the MSJCC, infusing them throughout training programs, and applying them in counseling practice to enrich counselor responsiveness and therapeutic change.

\subsection{Counseling Relationship and Cultural Humility}

One Evidence Based Relationship Factor (EBRF) identified as impacting client perception of treatment is cultural humility (Parrow et al. 2019). Cultural humility can be defined as "having an interpersonal stance that is other-oriented in relation to another individual's cultural background and experience, marked by respect for and lack of superiority toward another individual's cultural background and experience" (Hook et al. 2013, p. 361) or having "'cultural presence" or "way of being" with a client, which can facilitate trust and self-disclosure" (Owen et al. 2016, p. 34). Greater cultural humility by the counselor is connected to greater positive outcomes in counseling, when specifically rated by the clients (Owen et al. 2016). Cultural humility helps us to lessen the power dynamics in the relationship between the counselor and the client, reducing the privileged nature of being the counselor. The power, privilege, and oppression dynamics from counselors' and clients' lived experiences are not absent from the counseling relationship (O'Hara et al. 2021, p. 201). Owen et al. (2016) assert "it is not just being attentive to opportunities for conversations about identity and culture, but also how clients perceive that the therapist does this. Integral to cultural humility is how attuned a therapist is to recognizing power dynamics" (p. 35), with cultural humility allowing for an empowerment stance for the sake of the clients. Based on their findings, they recommend counselors bring up and explore identities relevant to the client, rather than those the counselor might see as relevant. Their findings point to the key of "inviting the client to self-define identity" (p. 34), allowing spiritual and religious factors as part of the intersectionality of the client's identity (Owen et al. 2016).

Counselors who display cultural humility consider how a client's various identities may intersect and consider this carefully in the work of developing the relationship with the client (Hook et al. 2013). Hook et al. (2013, pp. 361-62) provide a number of suggestions for integrating cultural humility into the work with clients, which have been revised here to specifically relate to spirituality/religion:

1. Remain humble as you engage with clients around spirituality and religion.

2. Be careful to not assume you understand the client's spirituality and religion based on your prior training, knowledge, or experiences.

3. Explore spirituality and religion with the client to determine what is positive and what might be detrimental in relation to their spirituality and religion.

4. Remain curious about the spirituality and religion of the client as such relates to the presenting issues, asking questions when appropriate.

When demonstrating cultural humility, counselors need to understand their own spirituality and religion, and seek to understand the client's spirituality and religion (Hook et al. 2013). Counselors do not need to let go of our own values, beliefs, and worldview. "If we are unable to face our own values openly, it means we are unable to face ourselves, which violates a primary principle of professional conduct in our field" (Bergin 1980, p. 102). The MSJCC focus on the importance of counselors knowing themselves, including their beliefs, values, and biases in order to gain a greater under- 
standing of their own worldview, which is critical to exploring their client's worldview (Ratts et al. 2016). Counselors must know their own values but focus on the client's values in order to ethically work within the client's worldview (American Counseling Association 2014). Through prioritizing a client's worldview, values, and identities throughout the counseling process, the counselor focuses on building the relationship with an end focus on positive outcomes for the client (Ridley et al. 2021a). Therefore, counselor self-awareness and cultural humility are foundational to MSJCC training in order to ensure that counselors can prioritize what is most important to the client during treatment.

\subsection{Looking Forward}

As counselors and counselor educators incorporate the MSJCC, it is essential that spirituality and religion are seen as fundamental cultural variables to be integrated into training and practice. As spirituality and religion are salient factors for many clients, it is important to consider a continuum of turning towards rather than turning away from the topics of spirituality and religion with our clients, supervisees, and students (Day-Vines et al. 2007; O'Hara et al. 2021). Counselors and counselor educators must move away from only including spirituality and religion briefly within an MCC course, mentioning it as a cursory topic, or avoiding the topic altogether. Inclusion also needs to move beyond a mechanical sense that seems forced rather than genuine. Instead, it is necessary that counselors and counselor educators find ways to infuse spirituality and religion appropriately throughout the training and work of counselors so that it becomes an integral part of the therapeutic process when salient to clients.

\section{Conclusions}

As Ratts et al. (2016) indicated five years ago, it takes time for the new MSJCC to be fully implemented into the counseling field. Given the original single-lens focus of the MCC with race and ethnicity privileged over other identities, the newer focus on the intersectionality of various identities will take time. Counselor educators, supervisors and counselors already in the field will need to be intentional about their own awareness and development of the new competencies amidst training new counselors under the MSJCC. The wider-lens of the MSJCC compels professional counselors to collaborate with clients to determine which identities are most salient to them, including spirituality and religion. As with all cultural factors, professional counselors must not minimize the importance and relevance of spirituality and religion to many clients as this can harm the relationship and ultimately the outcomes for the client. If spirituality and religion are considered from the perspective of the importance of the relationship, professional counselors will be able to be responsive to what matters most to each client. In focusing on relational responsiveness, professional counselors chose evidence-based practices not only to build the relationship, but to provide for greater treatment effectiveness.

Author Contributions: Both authors contributed to the research and writing of this paper. All authors have read and agreed to the published version of the manuscript.

Funding: This research received no external funding.

Conflicts of Interest: The authors declare no conflict of interest.

\section{References}

Adams, Jennifer R. 2012. Spiritual issues in counseling: What do students perceive they are being taught? Counseling and Values 57: 66-80. [CrossRef]

American Counseling Association. 2014. ACA Code of Ethics. Available online: http://www.counseling.org/docs/ethics/2014-acacode-of-ethics.pdf (accessed on 29 October 2021).

Asay, Ted P., and Michael J. Lambert. 1999. The empirical case for the common factors in therapy: Quantitative findings. In The Heart and Soul of Change: What Works in Therapy. Edited by Mark A. Hubble, Barry L. Duncan and Scott D. Miller. Washington, DC: American Psychological Association, pp. 23-55. [CrossRef] 
Bachelor, Alexandra, and Adam Horvath. 1999. The therapeutic relationship. In The Heart and Soul of Change: What Works in Therapy. Edited by Mark A. Hubble, Barry L. Duncan and Scott D. Miller. Washington, DC: American Psychological Association, pp. 133-78. [CrossRef]

Bell, Chance A., Sarah A. Crabtree, Eugene L. Hall, and Steven J. Sandage. 2021. Research in counselling and psychotherapy Post-COVID-19. Counselling and Psychotherapy Research 21: 3-7. [CrossRef] [PubMed]

Benish, Steven G., Zac E. Imel, and Bruce E. Wampold. 2008. The relative efficacy of bona fide psychotherapies for treating posttraumatic stress disorder: A meta-analysis of direct comparisons. Clinical Psychology Review 28: 746-58. [CrossRef] [PubMed]

Bergin, Allen E. 1980. Psychotherapy and religious values. Journal of Consulting and Clinical Psychology 48: 95-105. [CrossRef]

Bordin, Edward S. 1979. The generalizability of the psychoanalytic concept of the working alliance. Psychotherapy: Theory, Research $\mathcal{E}$ Practice 16: 252-60. [CrossRef]

Cashwell, Craig S., J. Scott Young, Cheryl L. Fulton, Ben T. Willis, Amanda Giordano, Laura Wyatt Daniel, Jamie Crockett, B. Nicole Tate, and Metoka L. Welch. 2013. Clinical behaviors for addressing religious/spiritual issues: Do we practice what we preach? Counseling and Values 58: 45-58. [CrossRef]

Castonguay, Louis G., Michael J. Constantino, and Martin Grosse Holtforth. 2006. The working alliance: Where are we and where should we go? Psychotherapy: Theory, Research, Practice, Training 43: 271-79. [CrossRef]

Council for Accreditation of Counseling and Related Educational Programs. 2016. 2016 CACREP Standards. Alexandria: Council for Accreditation of Counseling and Related Educational Programs. Available online: https://www.cacrep.org/for-programs/2016 -cacrep-standards / (accessed on 29 October 2021).

Crabtree, Sarah A., Chance A. Bell, David A. Rupert, Steven J. Sandage, Nancy G. Devor, and George Stavros. 2020. Humility, differentiation of self, and clinical training in spiritual and religious competence. Journal of Spirituality in Mental Health, 1-21. [CrossRef]

Day-Vines, Norma L., Susannah M. Wood, Tim Grothaus, Laurie Craigen, Angela Holman, Kylie Dotson-Blake, and Marcy J. Douglass. 2007. Broaching the subjects of race, ethnicity, and culture during the counseling process. Journal of Counseling E Development 85: 401-9.

Gallup. 2021. Religion. Available online: https:/ / news.gallup.com/poll/1690/Religion.aspx (accessed on 29 October 2021).

Garssen, Bert, Anja Visser, and Grieteke Pool. 2021. Does spirituality or religion positively affect mental health? Meta-analysis of longitudinal studies. The International Journal for the Psychology of Religion 31: 4-20. [CrossRef]

Giordano, Amanda L., and Craig S. Cashwell. 2014. Entering the sacred: Using motivational interviewing to address spirituality in counseling. Counseling and Values 59: 65-79. [CrossRef]

Gonzalez-Voller, Jessica, A. Elizabeth Crunk, Sejal M. Barden, Shaywanna Harris, and Christopher T. Belser. 2020. A preliminary longitudinal study of multicultural competence in counselor education. Journal of Counseling E Development 98: 308-18.

Gordon, Emma C. 2018. Intellectual humility, spirituality, and counselling. Journal of Psychology and Theology 46: 279-91. [CrossRef]

Harris, Kevin A., Brooke E. Randolph, and Timothy D. Gordon. 2016. What do clients want? Assessing spiritual needs in counseling: A literature review. Spirituality in Clinical Practice 3: 250-75. [CrossRef]

Hefti, René. 2011. Integrating religion and spirituality into mental health care, psychiatry and psychotherapy. Religions 2: 611-27. [CrossRef]

Henriksen, Richard C., Jr., Monica A. Polonyi, Jennifer N. Bornsheuer-Boswell, Rena G. Greger, and Richard E. Watts. 2015. Counseling students' perceptions of religious/spiritual counseling training: A qualitative study. Journal of Counseling E Development 93: 59-69.

Hook, Joshua N., Don E. Davis, Jesse Owen, Everett L. Worthington Jr., and Shawn O. Utsey. 2013. Cultural humility: Measuring openness to culturally diverse clients. Journal of Counseling Psychology 60: 353-66. [CrossRef] [PubMed]

Hook, Joshua N., Laura E. Captari, William Hoyt, Don E. Davis, Stacey E. McElroy, and Everett L. Worthington Jr. 2019. Religion and spirituality. In Psychotherapy Relationships That Work: Therapist Contributions and Responsiveness to Patients. Oxford: Oxford University Press, pp. 212-63.

Hubble, Mark A., Barry L. Duncan, and Scott D. Miller. 1999. The Heart and Soul of Change: What Works in Therapy. Washington, DC: American Psychological Association. [CrossRef]

Imel, Zac E., Bruce E. Wampold, Scott D. Miller, and Reg R. Fleming. 2008. Distinctions without a difference: Direct comparisons of psychotherapies for alcohol use disorders. Psychology of Addictive Behaviors 22: 533-43. [CrossRef] [PubMed]

Jain, Sachin, Joel A Lane, Derek J Smith, and Mansi Brat. 2017. Developing the nature of spiritual competency in a multiculturally competent counselor. Journal of Cultural Diversity 24: 126-35.

Leibert, Todd W. 2011. The dimensions of common factors in counseling. International Journal for the Advancement of Counselling 33: 127-38. [CrossRef]

Leibert, Todd W., and Alexandra Dunne-Bryant. 2015. Do common factors account for counseling outcome? Journal of Counseling $\mathcal{E}$ Development 93: 225-35. [CrossRef]

Leichsenring, Falk, and Eric Leibing. 2003. The effectiveness of psychodynamic therapy and cognitive behavior therapy in the treatment of personality disorders: A meta-analysis. American Journal of Psychiatry 160: 1223-32. [CrossRef]

Magaldi-Dopman, Danielle. 2014. An "afterthought": Counseling trainees' multicultural competence within the spiritual/religious domain. Journal of Multicultural Counseling and Development 42: 194-204. [CrossRef]

Miller, Geri. 1999. The development of the spiritual focus in counseling and counselor education. Journal of Counseling E Development 77: 498-501. 
Miller, Scott D., Mark A. Hubble, Barry L. Duncan, and Bruce E. Wampold. 2010. Delivering what works. In The Heart and Soul of Change: Delivering What Works in Therapy. Edited by Mark A. Hubble, Barry L. Duncan and Scott D. Miller. Washington, DC: American Psychological Association, pp. 421-29. [CrossRef]

Mintert, Jeffrey, Alisia GTT Tran, and Sharon Kurpius. 2020. Religious and/or spiritual social justice advocacy: Guidance from the multicultural and social justice counseling competencies. Counseling and Values 65: 2-14. [CrossRef]

Newport, Frank. 2020. The Religion Paradox. Gallup, May 8. Available online: https://news.gallup.com/opinion/polling-matters/31 0397 / religion-paradox.aspx (accessed on 29 October 2021).

Norcross, John C., ed. 2002. Psychotherapy Relationships That Work: Therapist Contributions and Responsiveness to Patients. Oxford: Oxford University Press.

Norcross, John C., and Bruce E. Wampold. 2018. A new therapy for each patient: Evidence-based relationships and responsiveness. Journal of Clinical Psychology 74: 1889-906. [CrossRef]

Norcross, John C., and Bruce E. Wampold. 2019. Evidence-based psychotherapy responsiveness: The third task force. Psychotherapy Relationships That Work 2: 1-14.

O'Hara, Caroline, Catherine Y. Chang, and Amanda L. Giordano. 2021. Multicultural competence in counseling research: The cornerstone of scholarship. Journal of Counseling \& Development 99: 200-9.

Owen, Jesse, Karen W. Tao, Joanna M. Drinane, Joshua Hook, Don E. Davis, and Natacha Foo Kune. 2016. Client perceptions of therapists' multicultural orientation: Cultural (missed) opportunities and cultural humility. Professional Psychology: Research and Practice 47: 30-37. [CrossRef]

Parrow, Kimberly K., John Sommers-Flanagan, J. Sky Cova, and Hugo Lungu. 2019. Evidence-based relationship factors: A new focus for mental health counseling research, practice, and training. Journal of Mental Health Counseling 41: 327-42. [CrossRef]

Pearce, Michelle J., Kenneth I. Pargament, Holly K. Oxhandler, Cassandra Vieten, and Serena Wong. 2019. A novel training program for mental health providers in religious and spiritual competencies. Spirituality in Clinical Practice 6: 73-82. [CrossRef]

Ratts, Manivong J., Anneliese A. Singh, Sylvia Nassar-McMillan, S. Kent Butler, and Julian Rafferty McCullough. 2016. Multicultural and social justice counseling competencies: Guidelines for the counseling profession. Journal of Multicultural Counseling and Development 44: 28-48. [CrossRef]

Ratts, Manivong J., Anneliese A. Singh, Sylvia Nassar-McMillan, S. Kent Butler, Julian Rafferty McCullough, and Carlos HipolitoDelgado. 2015. Multicultural and Social Justice Counseling Competencies. Available online: https://www.counseling.org/docs/ default-source/competencies / multicultural-and-social-justice-counseling-competencies.pdf?sfvrsn=14 (accessed on 29 October 2021).

Ridley, Charles R., Ankita Sahu, Katie Console, Shruti Surya, Vy Tran, Siming Xie, and Caroliina Yin. 2021a. The process model of multicultural counseling competence. The Counseling Psychologist 49: 534-67. [CrossRef]

Ridley, Charles R., Debra Mollen, Katie Console, and Caroliina Yin. 2021b. Multicultural counseling competence: A construct in search of operationalization. The Counseling Psychologist 49: 504-33. [CrossRef]

Scott, Stephanie K., Donna S. Sheperis, Robyn Trippany Simmons, Tiffany Rush-Wilson, and Lori A. Milo. 2016. Faith as a cultural variable: Implications for counselor training. Counseling and Values 61: 192-205. [CrossRef]

Sue, Derald Wing, Joseph E. Bernier, Anna Durran, Lawrence Feinberg, Paul Pedersen, Elsie J. Smith, and Ena Vasquez-Nuttall. 1982. Position paper: Cross-cultural counseling competencies. The Counseling Psychologist 10: 45-52. [CrossRef]

Sue, Derald Wing, Patricia Arredondo, and Roderick J. McDavis. 1992. Multicultural counseling competencies and standards: A call to the profession. Journal of Counseling \& Development 70: 477-86.

Tryon, Georgiana S., Sasha C. Blackwell, and Elizabeth F. Hammel. 2007. A meta-analytic examination of client-therapist perspectives of the working alliance. Psychotherapy Research 17: 629-42. [CrossRef]

Vandiver, Beverly J., Edward A. Delgado-Romero, and William Ming Liu. 2021. Is Multicultural Counseling Competence Outdated or Underdeveloped, or in Need of Refinement? A Response to Ridley et al. The Counseling Psychologist 49: 586-609. [CrossRef]

Wampold, Bruce E. 2001. The Great Psychotherapy Debate: Models, Methods, and Findings. Mahwah: Lawrence Erlbaum Associates Publishers.

Wampold, Bruce E., and Zac E. Imel. 2015. The Great Psychotherapy Debate: The Evidence for What Makes Psychotherapy Work. New York: Routledge.

Whitley, Rob. 2012. Religious competence as cultural competence. Transcultural Psychiatry 49: 245-60. [CrossRef] [PubMed]

Zimmermann, Dirk, Bruce E. Wampold, Julian A. Rubel, Brian Schwartz, Kaitlyn Poster, Viola N. L. S. Schilling, Anne-Katharina Deisenhofer, Miriam I. Hehlmann, Juan Martín Gómez Penedo, and Wolfgang Lutz. 2020. The influence of extra-therapeutic social support on the association between therapeutic bond and treatment outcome. Psychotherapy Research 31: 726-36. [CrossRef] 